\title{
Above-belowground interactions in alpine ecosystems on the roof of the world
}

\author{
Jin-Sheng He(D) - Shikui Dong • Zhanhuan Shang • \\ Maja K. Sundqvist • Gaolin Wu • Yunfeng Yang
}

Received: 27 October 2020 / Accepted: 30 October 2020/Published online: 5 November 2020

(C) Springer Nature Switzerland AG 2020

The Tibetan Plateau, known as the "Roof of the world", is the highest plateau on Earth. It is the origin of major Asian rivers, and hence also called the "Asian Water Tower". The plateau has unique ecosystems, characterized by low temperatures and low atmospheric pressure and oxygen concentrations. Despite extreme environmental conditions, the plateau exhibits a rich biodiversity. Over the past several decades, the plateau has experienced rapid climate change and intensified human activities. For instance, the mean annual air temperature has increased by about $0.4{ }^{\circ} \mathrm{C}$ per decade since the 1970 s which is twice that of the global average (Fig. 1). The alpine ecosystems, including interacting plants, animals and microorganisms, and above- and

Editorial Responsibility: Hans Lambers

\section{J.-S. He}

State Key Laboratory of Grassland Agro-ecosystems, College of Pastoral Agriculture Science and Technology, Lanzhou University, 768 Jiayuguan W Road, Lanzhou 730020, China

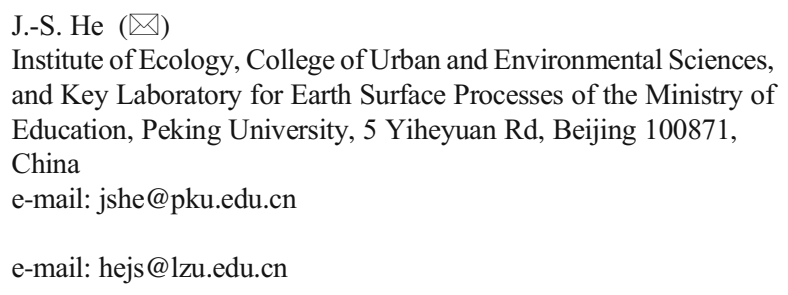

belowground components, are the results of long-term evolution and adaptation to the extreme environments. Understanding how the alpine environments shape above-belowground interactions and their responses to climate change remains a huge challenge.

In recent decades, extensive efforts have been made to examine the structure and functioning of Tibetan alpine ecosystems, including field observations, transect surveys, well-designed experiments, comprehensive meta-analyses, and literature reviews. Currently, we can draw the following conclusions:

- The alpine ecosystem is a relatively large carbon pool, especially the peat in alpine wetlands and soils

\section{Z. Shang}

State Key Laboratory of Grassland Agro-ecosystems, School of Life Sciences, Lanzhou University, Lanzhou 730000, China

\section{K. Sundqvist}

Department of Earth Sciences, University of Gothenburg, 40530 Gothenburg, Sweden

G. Wu

State Key Laboratory of Soil Erosion and Dryland Farming on the Loess Plateau, Institute of Soil and Water Conservation, Chinese Academy of Sciences and Ministry of Water Resource, Yangling 712100 Shaanxi, China

Y. Yang

State Key Joint Laboratory of Environment Simulation and Pollution Control, School of Environment, Tsinghua University, Beijing 100084, China 
(a)
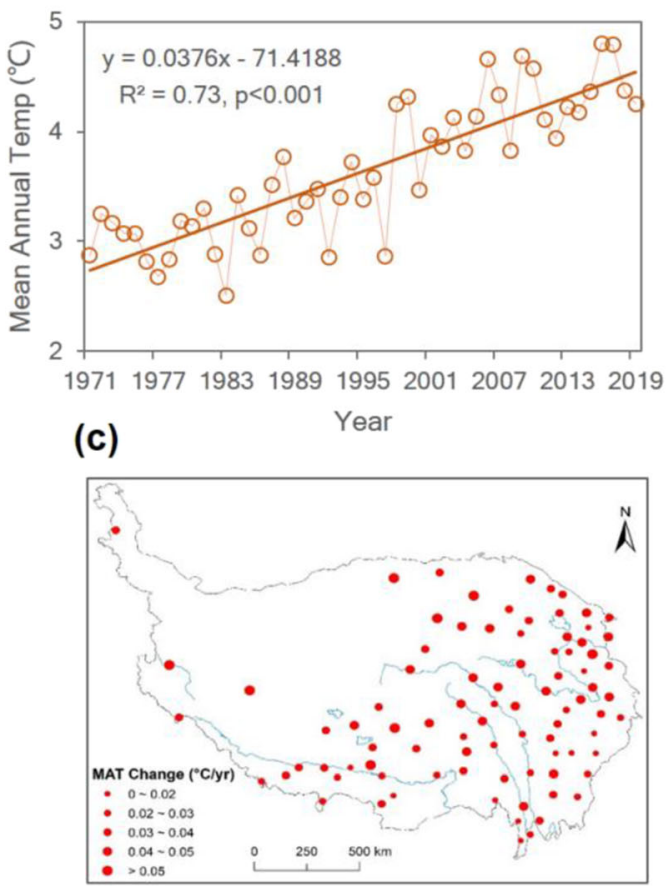

(b)
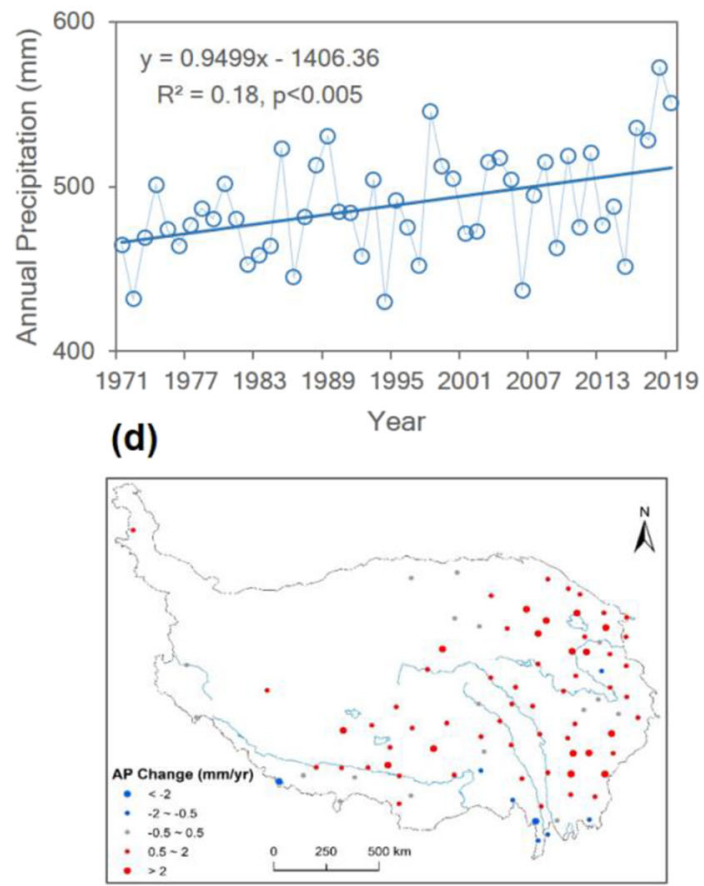

Fig. 1 Changes in mean annual temperature and annual precipitation form 1971 to 2019 on the Tibetan Plateau. From 1971 onwards, the plateau has experienced faster climate warming than the global average

in alpine meadows. Alarmingly, this carbon pool is threatened by global warming and permafrost melting (Ding et al. 2016; Tang et al. 2018; Chen et al. 2019; Kou et al. 2020).

- The alpine grasslands, occupying more than $50 \%$ of the total area of the Tibetan Plateau, have shown an increasing trend in vegetation growth in the past several decades. This greening trend is mainly caused by climate change, and to a lesser extent by ecosystem restoration projects (Zhang et al. 2015; Shen et al. 2015; Liu et al. 2019).

- Data from long-term monitoring, remote sensing, and controlled experiments indicate that climate change is altering and reshaping patterns of vegetation growth, and these changes will have cascading effects on the structure and functioning of alpine ecosystems ( $\mathrm{Li}$ et al. 2016; Ma et al. 2017; Liu et al. 2018; Wang et al. 2020a).

- The biogeographic patterns of soil microbial communities on the Tibetan Plateau are determined by above- and belowground parameters, such as vegetation type, soil $\mathrm{pH}$, and moisture, and strongly influenced by climate changes (Jing et al. 2015;
Zhang et al. 2016; Ladau et al. 2018; Jiang et al. 2018).

- Although the overall vegetation growth on the Tibetan Plateau is increasing, the grassland ecosystems in some areas are still severely degraded (Dong et al. 2020). Preserving the pristine condition of the typical alpine vegetation and restoring the integrity of degraded ecosystems to achieve sustainable and environmentally-sound ecosystem management are the main on-going research topics (Bai et al. 2020; He et al. 2020).

Despite remarkable knowledge gains, there are still some areas that require in-depth research, such as the above-belowground interactions of alpine ecosystems. It is particularly important for this system for the following reasons: (1) A large part of the alpine ecosystem resources is allocated belowground. This may be more than $80 \%$ in alpine grassland. (2) Under extreme environmental conditions, plants may rely more on symbiotic associations with microorganisms. (3) The rapid climate change of the Tibetan Plateau may have a significant impact on above- and belowground interactions. 


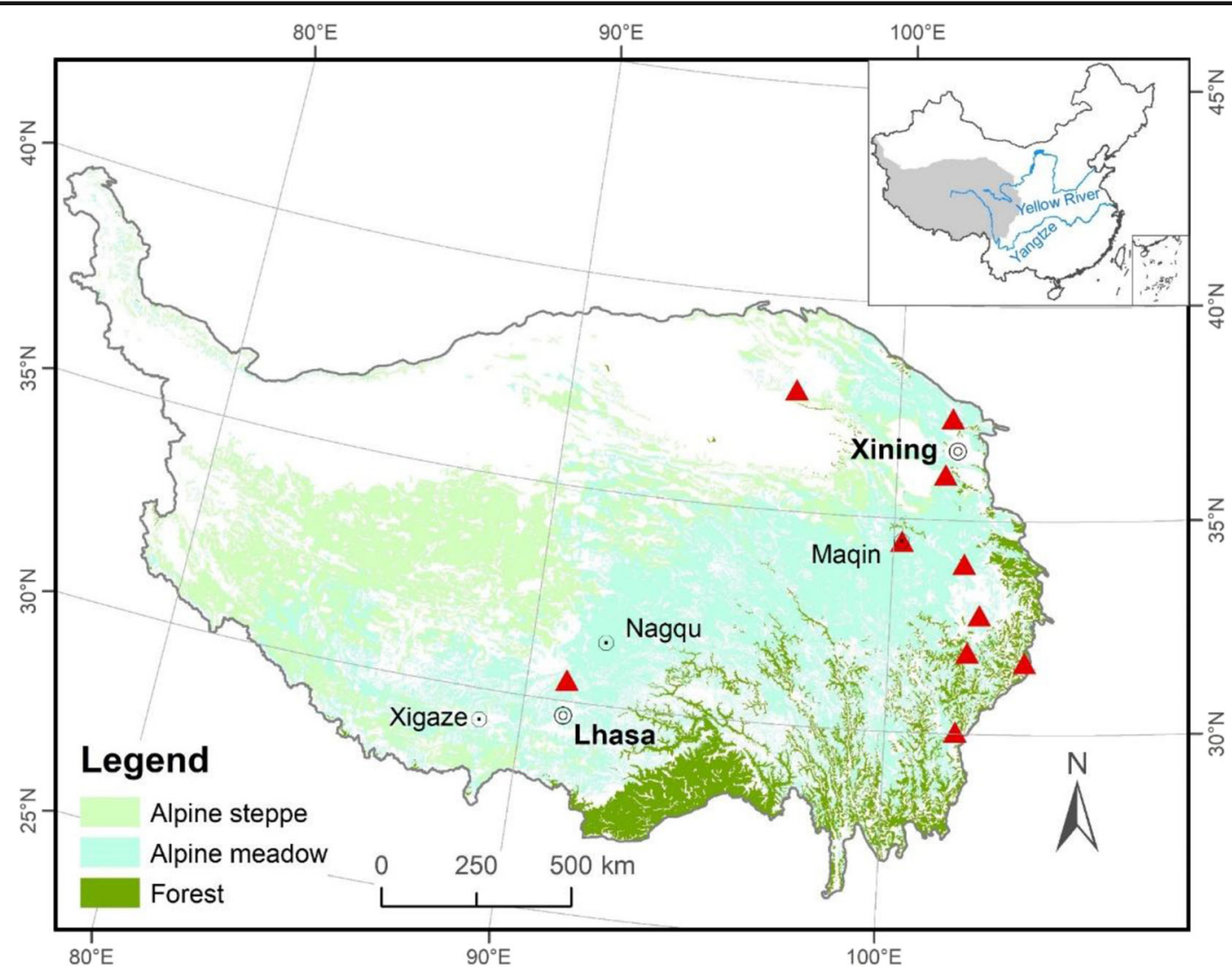

Fig. 2 A vegetation map of the Tibetan Plateau, showing the research sites used for studies described in this Special Issue

To advance our understandings of the abovebelowground interactions in the alpine ecosystems, we organized a Special Issue entitled "Above-belowground interactions in alpine ecosystems on the roof of the world". This Special Issue comprises 19 articles, spanning multiple alpine ecosystems, including forests, shrublands, meadows, steppes, and marshes, across the eastern and southern parts of the Tibetan Plateau (Fig. 2), and covering diverse ecological processes.

Three papers in this Special Issue discuss the changes in above- and belowground ecological processes along altitudinal gradients. Specifically, Cui et al. (2020) explored the characteristics of microbial metabolic limitations along an altitudinal gradient. Hou et al. (2020) assessed the patterns of soil organic matter stability along two altitudinal gradients, and found that the soil organic matter stability was jointly controlled by edaphic, vegetation, and climatic factors. Yao et al. (2020) found that the quantity and quality of soil organic matter, in addition to leaf cuticular waxes, varied with altitude.
Several papers in this Special Issue assess the effect of climate change on above- and belowground ecological processes. Liu et al. (2020) found that experimentally simulating a warmer and drier climate enhanced root production, but reduced root decomposition in an alpine grassland. Wang et al. (2020b) found in a field that precipitation mediated the warming effects on soil respiration. Chen et al. (2020) found that long-term nitrogen deposition decreased the less-protected particulate organic carbon, while the mineral-associated organic carbon was less vulnerable. Zhong et al. (2020) found that altered precipitation and foliar endophytes jointly affected root-associated arbuscular mycorrhizal fungal diversity for a common alpine grass species, Achnatherum inebrians.

The Tibetan Plateau is home to one of the most extensive rangelands in the world. Livestock grazing, as the common practice in this ecosystem, is largely shaping community structure and ecosystem functioning. Mipam et al. (2020) found that the plant and soil nutrients stoichiometry did not covary under different grazing intensities. Sun et al. (2020) found that 
the plants tended to allocate more biomass belowground under moderate grazing intensity than under light and heavy grazing intensities, supporting the optimal biomass partitioning hypothesis, rather than the isometric allocation hypothesis. Tian et al. (2020) showed that plant diversity and soil carbon sequestration were differently affected by warm- and cold-season grazing, highlighting the importance of considering the grazing strategies in maintaining ecosystem sustainability. Zhang et al. (2020) found that clipping increased ecosystem carbon sequestration in an alpine meadow, and clipping could modulate carbon sequestration in response to changes in precipitation. In parallel, Yin et al. (2020) found that 10 years of preventing grazing was not beneficial to community structure of functional microorganisms. In agreement with Yin et al. (2020), $\mathrm{Wu}$ et al. (2020) also found that long-term exclosure fencing decreased plant diversity and soil organic carbon sequestration.

The burrowing activities from small rodents such as plateau pika (Ochotona curzoniae) are considered one of the main reasons for grassland degradation on the Tibetan Plateau. Qin et al. (2020) found that vegetation growth and soil carbon were susceptible to foraging and burrowing activities of pikas. Similarly, Zhao et al. (2020) found that ecosystem respiration was lower in the bare soil caused by burrowing activities of pika than in vegetated soil. Dai et al. (2020) found that the deteriorated soil structure caused by grassland degradation affected soil water retention. Xu et al. (2020) showed that ectomycorrhizal and rhizosphere fungal communities responded differently during forest restoration.

Two articles reveal interesting phenomena in this unique ecosystem. Wang et al. (2020c) found that $\mathrm{N}_{2}$ fixing plants improved the resource status and were beneficial for establishing neighboring plants in a newly formed glacier floodplain. Wang et al. (2020d) found that the deciduous tree species tended to release more root exudates than evergreen tree species, and consequently led to greater microbial feedback on nutrient cycling.

Although some results on the ecology of the Tibetan Plateau may still be somewhat preliminary, all studies included in this Special Issue have undoubtedly improved our understanding of the above-belowground interactions in these alpine ecosystems. Some important questions remain. One major hot topic in recent years has been the structure and functioning of aboveground and belowground food webs and their responses to climate change. This is very important for alpine ecosystems, because the interdependence and interactions among organisms in extreme environments are fragile, and they are most vulnerable to climate change and human activities. Unfortunately, we know very little, and have almost no empirical evidence in this respect. Another focus comes from some special features on the Tibetan Plateau, such as glaciers, permafrost, and seasonally-frozen soils associated with low temperature and high elevations. As climate warming continues, how retreating glaciers, rising snowlines, and thawing permafrost will affect above- and belowground interactions needs special attention. In addition, the majority of the studies included in this Special Issue were conducted at the eastern side of the Tibetan Plateau, where the influence of human activity is relatively stronger. Thus, further explorations need to focus on the western side of the Tibetan Plateau, where some pristine ecosystem types dominate. With the advancement of science and technology, such as unattended observation equipment, internet in remote areas, molecular technologies such as meta-genomics, -transcriptomics, -proteomics, and metabolomics, the study of aboveground-belowground interactions of ecosystems in extreme environments is expected to make great progress soon.

Acknowledgments The idea of organizing this Special Issue originated at an international conference held in Lanzhou in 2018. Dr. Hans Lambers was an invited speaker at the plenary session of the conference. During the meeting, many studies focused on above- and belowground interactions of the alpine ecosystem on the Tibetan Plateau, which interested Dr. Hans Lambers, who offered help towards this Special Issue. We would like to thank all authors, reviewers, and Editors, whose great efforts have made this Special Issue possible. Huiying Liu and Qisheng Feng helped to prepare the figures and organize part of the text. JSH is supported by Lanzhou University and funding agencies: Key R\&D Projects of the Ministry of Science and Technology of China (2019YFC0507701) and National Natural Science Foundation of China (Grants No. 31630009).

\section{References}

Bai Y, Ma L, Degen AA, Rafiq MK, Kuzyakov Y, Zhao J, Zhang R, Zhang T, Wang W, Li X, Long R, Shang Z (2020) Longterm active restoration of extremely degraded alpine grassland accelerated turnover and increased stability of soil carbon. Glob Chang Biol. https://doi.org/10.1111/gcb.15361

Chen L, Liu L, Qin S, Yang G, Fang K, Zhu B, Kuzyakov Y, Chen P, Xu Y, Yang Y (2019) Regulation of priming effect by soil organic matter stability over a broad geographic scale. Nat 
Commun 10:5112. https://doi.org/10.1038/s41467-01913119-Z

Chen Y, Liu X, Hou Y, Zhou S, Zhu B (2020) Particulate organic carbon is more vulnerable to nitrogen addition than mineralassociated organic carbon in soil of an alpine meadow. Plant Soil. https://doi.org/10.1007/s11104-019-04279-4

Cui Y, Bing H, Fang L, Jiang M, Shen G, Yu J, Wang X, Zhu H, Wu Y, Zhang X (2020) Extracellular enzyme stoichiometry reveals the carbon and phosphorus limitations of microbial metabolisms in the rhizosphere and bulk soils in alpine ecosystems. Plant Soil. https://doi.org/10.1007/s11104-01904159-x

Dai L, Guo X, Ke X, Du Y, Zhang F, Cao G (2020) The variation in soil water retention of alpine shrub meadow under different degrees of degradation on northeastern Qinghai-Tibetan plateau. Plant Soil. https://doi.org/10.1007/s11104-02004522-3

Ding J, Li F, Yang G, Chen L, Zhang B, Liu L, Fang K, Qin S, Chen Y, Peng Y, Ji C, He H, Smith P, Yang Y (2016) The permafrost carbon inventory on the Tibetan plateau: a new evaluation using deep sediment cores. Glob Chang Biol 22: 2688-2701. https://doi.org/10.1111/gcb.13257

Dong S, Shang Z, Gao J, Boone RB (2020) Enhancing sustainability of grassland ecosystems through ecological restoration and grazing management in an era of climate change on Qinghai-Tibetan plateau. Arid Ecosyst Environ 287:106684. https://doi.org/10.1016/j.agee.2019.106684

He J-S, Bu H, Hu X, Feng Y, Li S, Zhu J, Liu G, Wang Y, Nan Z (2020) Close-to-nature restoration of degraded alpine grasslands: theoretical basis and technical approach. Chin Sci Bull 65:3898-3908. https://doi.org/10.1360/TB-2020-0405

Hou Y, He K, Chen Y, Zhao J, Hu H, Zhu B (2020) Changes of soil organic matter stability along altitudinal gradients in Tibetan alpine grassland. Plant soil. https://doi.org/10.1007 /s11-104-019-04351-Z

Jiang S, Liu Y, Luo J, Qin M, Johnson NC, Öpik M, Vasar M, Chai Y, Zhou X, Mao L, Du G, An L, Feng H (2018) Dynamics of arbuscular mycorrhizal fungal community structure and functioning along a nitrogen enrichment gradient in an alpine meadow ecosystem. New Phytol 220:12221235. https://doi.org/10.1111/nph.15112

Jing X, Sanders NJ, Shi Y, Chu H, Classen AT, Zhao K, Chen L, Shi Y, Jiang Y, He J-S (2015) The links between ecosystem multifunctionality and above- and belowground biodiversity are mediated by climate. Nat Commun 6:8159. https://doi. org/10.1038/ncomms9159

Kou D, Yang G, Li F, Feng X, Zhang D, Mao C, Zhang Q, Peng Y, Ji C, Zhu Q, Fang Y, Liu X, Xu R, Li S, Deng J, Zheng X, Fang J, Yang Y (2020) Progressive nitrogen limitation across the Tibetan alpine permafrost region. Nat Commun 11:3331. https://doi.org/10.1038/s41467-020-17169-6

Ladau J, Shi Y, Jing X, He J-S, Chen L, Lin X, Fierer N, Gilbert JA, Pollard KS, Chu H (2018) Existing climate change will lead to pronounced shifts in the diversity of soil prokaryotes. mSystems 3:e00167-e00118. https://doi.org/10.1128 /mSystems.00167-18

Li X, Jiang L, Meng F, Wang S, Niu H, Iler AM, Duan J, Zhang Z, Luo C, Cui S, Zhang L, Li Y, Wang Q, Zhou Y, Bao X, Dorji T, Li Y, Penuelas J, Du M, Zhao X, Zhao L, Wang G (2016) Responses of sequential and hierarchical phenological events to warming and cooling in alpine meadows. Nat Commun 7: 12489. https://doi.org/10.1038/ncomms 12489

Liu D, Wang T, Yang T, Yan Z, Liu Y, Zhao Y, Piao S (2019) Deciphering impacts of climate extremes on Tibetan grasslands in the last fifteen years. Sci Bull 64:446-454. https://doi.org/10.1016/j.scib.2019.03.012

Liu H, Lin L, Wang H, Zhang Z, Sg Z, Feng X, He J-S (2020) Simulating warmer and drier climate increases root production but decreases root decomposition in an alpine grassland on the Tibetan plateau. Plant Soil. https://doi.org/10.1007 /s11104-020-04551-y

Liu H, Mi Z, Lin L, Wang Y, Zhang Z, Zhang F, Wang H, Liu L, Zhu B, Cao G, Zhao X, Sanders NJ, Classen AT, Reich PB, He J-S (2018) Shifting plant species composition in response to climate change stabilizes grassland primary production. Proc Natl Acad Sci U S A 115:4051-4056. https://doi. org/10.1073/pnas.1700299114

Ma Z, Liu H, Mi Z, Zhang Z, Wang Y, Xu W, Jiang L, He J-S (2017) Climate warming reduces the temporal stability of plant community biomass production. Nat Commun 8: 15378. https://doi.org/10.1038/ncomms 15378

Mipam TD, Chen S, Liu J, Miehe G, Tian L (2020) Short-term yak-grazing alters plant-soil stoichiometric relations in an alpine meadow on the eastern Tibetan plateau. Plant Soil. https://doi.org/10.1007/s11104-019-04401-6

Qin Y, Yi S, Ding Y, Qin Y, Zhang W, Sun Y, Hou X, Yu H, Meng B, Zhang H, Chen J, Wang Z (2020) Effects of plateau pikas' foraging and burrowing activities on vegetation biomass and soil organic carbon of alpine grasslands. Plant Soil. https://doi.org/10.1007/s11104-020-04489-1

Shen M, Piao S, Jeong S-J, Zhou L, Zeng Z, Ciais P, Chen D, Huang M, Jin C-S, Li LZX, Li Y, Myneni RB, Yang K, Zhang G, Zhang Y, Yao T (2015) Evaporative cooling over the Tibetan plateau induced by vegetation growth. Proc Natl Acad Sci U S A 112:9299-9304. https://doi.org/10.1073 /pnas. 1504418112

Sun J, Zhan T, Liu M, Zhang Z, Wang Y, Liu S, Wu G, Liu G, Tsunekawa A (2020) Verification of the biomass transfer hypothesis under moderate grazing across the Tibetan plateau: a meta-analysis. Plant Soil. https://doi.org/10.1007 /s11104-019-04380-8

Tang X, Zhao X, Bai Y, Tang Z, Wang W, Zhao Y, Wan H, Xie Z, Shi X, Wu B, Wang G, Yan J, Ma K, Du S, Li S, Han S, Ma Y, Hu H, He N, Yang Y, Han W, He H, Yu G, Fang J, Zhou G (2018) Carbon pools in China's terrestrial ecosystems: new estimates based on an intensive field survey. Proc Natl Acad Sci U S A 115:4021-4026. https://doi.org/10.1073 /pnas.1700291115

Tian L, Bai Y, Wang W, Qu G, Deng Z, Li R, Zhao J (2020) Warm- and cold- season grazing affect plant diversity and soil carbon and nitrogen sequestration differently in Tibetan alpine swamp meadows. Plant Soil. https://doi.org/10.1007 /s11104-020-04573-6

Wang H, Liu H, Cao G, Ma Z, Li Y, Zhang F, Zhao X, Zhao X, Jiang L, Sanders NJ, Classen AT, He J-S (2020a) Alpine grassland plants grow earlier and faster but biomass remains unchanged over 35 years of climate change. Ecol Lett 23: 701-710. https://doi.org/10.1111/ele.13474

Wang J, He Q, Wu Y, Zhu H, Sun H, Zhou J, Wang D, Li J, Bing $\mathrm{H}$ (2020b) Effects of pioneer $\mathrm{N}_{2}$-fixing plants on the resource status and establishment of neighboring non- $\mathrm{N}_{2}$-fixing plants 
in a newly formed glacier floodplain, eastern Tibetan plateau. Plant Soil. https://doi.org/10.1007/s11104-020-04462-y

Wang QT, Xiao J, Ding JX, Zou TT, Zhang ZL, Liu Q, Yin HJ (2020c) Differences in root exudate inputs and rhizosphere effects on soil $\mathrm{N}$ transformation between deciduous and evergreen trees. Plant Soil. https://doi.org/10.1007/s11104019-04156-0

Wang Y, Song C, Liu H, Wang S, Zeng H, Luo C, He J-S (2020d) Precipitation determines the magnitude and direction of interannual responses of soil respiration to experimental warming. Plant Soil. https://doi.org/10.1007/s11104-02004438-y

Wu X, Wang Y, Sun S (2020) Long-term fencing decreases plant diversity and soil organic carbon concentration of the Zoige alpine meadows on the eastern Tibetan plateau. Plant Soil. https://doi.org/10.1007/s11104-019-04373-7

Xu G, Chen H, Shi Z, Liu S, Cao X, Zhang M, Chen M, Chen J, Xiong K, Yang H, Zhao G (2020) Mycorrhizal and rhizospheric fungal community assembly differs during subalpine forest restoration on the eastern Qinghai-Tibetan plateau. Plant soil. https://doi.org/10.1007/s11104-019-04400-7

Yao L, Guo N, He Y, Xiao Y, Li Y, Gao J, Guo Y (2020) Variations of soil organic matters and plant cuticular waxes along an altitude gradient in Qinghai-Tibet plateau. Plant Soil. https://doi.org/10.1007/s11104-019-04304-6

Yin Y, Wang Y, Li S, Liu Y, Zhao W, Ma Y, Bao G (2020) Soil microbial character response to plant community variation after grazing prohibition for 10 years in a Qinghai-Tibetan alpine meadow. Plant Soil. https://doi.org/10.1007/s11104019-04044-7
Zhang F, Quan Q, Ma F, Zhou Q, Niu S (2020) Clipping increases ecosystem carbon sequestration and its sensitivity to precipitation change in an alpine meadow. Plant Soil. https://oi. org/10.1007/s11104-019-04278-5

Zhang K, Shi Y, Jing X, He J-S, Sun R, Yang Y, Shade A, Chu H (2016) Effects of short-term warming and altered precipitation on soil microbial communities in alpine grassland of the Tibetan plateau. Front Microbiol 7:1032. https://doi. org/10.3389/fmicb.2016.01032

Zhang X, Yang Y, Piao S, Bao W, Wang S, Wang G, Sun H, Luo T, Zhang Y, Shi P, Liang E, Shen M, Wang J, Gao Q, Zhang Y, Ouyang H (2015) Ecological change on the Tibetan plateau (in Chinese). Chin Sci Bull 60:3048-3056. https://doi.org/10.1360/n972014-01339

Zhao J, Tian L, Wei H, Zhang T, Bai Y, Li R, Tang Y (2020) Impact of plateau pika (Ochotona curzoniae) burrowinginduced microtopography on ecosystem respiration of the alpine meadow and steppe on the Tibetan plateau. Plant Soil. https://doi.org/10.1007/s11104-019-04122-w

Zhong R, Xia C, Ju Y, Zhang X, Duan T, Nan Z, Li C (2020) A foliar Epichloë endophyte and soil moisture modified belowground arbuscular mycorrhizal fungal biodiversity associated with Achnatherum inebrians. Plant Soil. https://doi. org/10.1007/s11104-019-04365-7

Publisher's note Springer Nature remains neutral with regard to jurisdictional claims in published maps and institutional affiliations. 